\title{
Sustained inhibition of progressive joint damage with rituximab plus methotrexate in early active rheumatoid arthritis: 2-year results from the randomised controlled trial IMAGE
}

\author{
Paul P Tak, ${ }^{1}$ William Rigby, ${ }^{2}$ Andrea Rubbert-Roth, ${ }^{3}$ Charles Peterfy, ${ }^{4}$ \\ Ronald F van Vollenhoven, ${ }^{5}$ William Stohl, ${ }^{6}$ Emma Healy, ${ }^{7}$ Eva Hessey, \\ Mark Reynard, ${ }^{7}$ Tim Shaw $^{7}$
}

\begin{abstract}
- Additional supplementary data are published online only. To view these files please visit the journal online (http://ard. bmj.com/content/71/3.toc)
\end{abstract}

1 Division of Clinical Immunology and Rheumatology, Academic Medical Centre/University of Amsterdam, Amsterdam, The Netherlands

2Department of Medicine, Dartmouth Medical School/ Dartmouth-Hitchcock Medical

Centre, Lebanon, New Hampshire, USA

${ }^{3}$ Department of Internal Medicine, University of Cologne,

Cologne, Germany

${ }^{4}$ Spire Sciences LLC, San

Francisco, California, USA

${ }^{5}$ Department of Medicine,

The Karolinska Institute,

Stockholm, Sweden

${ }^{6}$ Department of Medicine, Division of Rheumatology, Los Angeles County/University of Southern California Medical Centre and University of Southern California Keck School of Medicine, Los Angeles, California, USA

${ }^{7}$ Roche Products, Welwyn Garden City, UK

\section{Correspondence to}

Professor Paul P Tak, Division of Clinical Immunology and

Rheumatology, Academic Medical Centre/University of Amsterdam, F4-105, P 0 Box 22700, 1100 DE Amsterdam, The Netherlands: p.p.tak@amc.uva.nl

Received 13 May 2011 Accepted 10 September 2011 Published Online First 19 October 2011

\section{ABSTRACT \\ Background In the IMAGE study, rituximab plus} methotrexate (MTX) inhibited joint damage and improved clinical outcomes at 1 year in MTX-naïve patients with early active rheumatoid arthritis.

Objective The aim of this study was to assess joint damage progression and clinical outcomes over 2 years.

Methods Patients $(n=755)$ were randomised to receive rituximab $2 \times 500 \mathrm{mg}+\mathrm{MTX}, 2 \times 1000 \mathrm{mg}+\mathrm{MTX}$ or placebo + MTX. The placebo-controlled period continued to week 104. Two-year end points were defined as secondary or exploratory and included change in total Genant-modified Sharp score (mTSS), total erosion score and joint space narrowing score from baseline to week 104. Clinical efficacy and physical function end points were also assessed.

Results At 2 years, rituximab $2 \times 1000 \mathrm{mg}+\mathrm{MTX}$ maintained inhibition of progressive joint damage versus MTX alone (mTSS change 0.41 vs 1.95; $p<0.0001$ (79\% inhibition)), and a higher proportion of patients receiving rituximab $2 \times 1000 \mathrm{mg}+\mathrm{MTX}$ had no radiographic progression over 2 years compared with those receiving MTX alone ( $57 \%$ vs $37 \% ; p<0.0001$ ). Contrary to 1 -year results, exploratory analysis of rituximab $2 \times 500 \mathrm{mg}+\mathrm{MTX}$ at 2 years showed that progressive joint damage was slowed by $\sim 61 \%$ versus placebo + MTX (mTSS, exploratory $p=0.0041$ ). Improvements in clinical signs and symptoms and physical function seen after 1 year in rituximab-treated patients versus those receiving placebo were maintained at year 2. Safety profiles were similar between groups.

Conclusions Treatment with rituximab

$2 \times 1000 \mathrm{mg}+\mathrm{MTX}$ was associated with sustained improvements in radiographic, clinical and functional outcomes over 2 years.

Clinical trials.gov identifier NCT00299104.

\section{INTRODUCTION}

Rheumatoid arthritis (RA) is a chronic inflammatory disease in which joint damage and physical disability adversely affect quality of life and increase morbidity and premature mortality. ${ }^{12}$ Recent recommendations suggest that early treatment should be targeted towards the goal of clinical remission or low disease activity (LDA) and that this can lead to better structural and functional outcomes for patients. Furthermore, remission or LDA should be maintained throughout the course of the disease. ${ }^{34}$ In addition to clinical targets, maintaining inhibition of joint damage is important for the patient, given the association between structural damage and long-term loss of function. ${ }^{5}$

B cell depletion with rituximab $2 \times 1000 \mathrm{mg}$ is an established and effective treatment for RA. In combination with methotrexate (MTX), rituximab has been shown to significantly reduce clinical signs and symptoms of RA in patients with an inadequate response (IR) to either conventional disease-modifying antirheumatic drugs or tumour necrosis factor (TNF) inhibitors ${ }^{6-9}$ and to inhibit radiographic progression in TNF-IR patients. ${ }^{9-11}$ In the IMAGE study-a randomised placebo-controlled trial of rituximab plus MTX in MTX-naive patients with early active RA-rituximab $2 \times 1000 \mathrm{mg}+$ MTX significantly inhibited progression of joint damage and improved clinical outcomes and physical function compared with MTX alone after 1 year. ${ }^{1213}$ Here, we present clinical and radiographic outcomes from the 2-year analysis of this study.

\section{METHODS}

Full eligibility criteria have been previously reported. ${ }^{12}$ In brief, patients were required to have a disease duration of $\geq 8$ weeks but $\leq 4$ years, no prior MTX treatment and active disease (swollen joint count (66 joints) and tender joint count ( 68 joints) both $\geq 8$ at screening and baseline, and Creactive protein level $\geq 1.0 \mathrm{mg} / \mathrm{dl}$ ). Patients seronegative for rheumatoid factor (RF) were only eligible if they had radiographic evidence of erosive damage attributable to RA. This study was conducted in accordance with the Declaration of Helsinki and was approved by the institutional review board or the ethics committee at each study site. All patients gave written informed consent.

In October 2009, following a spontaneous report outside of clinical trials of a case of progressive multifocal leucoencephalopathy (PML) in a rituximab-treated patient not previously treated with biologics, rituximab treatment was discontinued in the IMAGE trial and patients were subjected instead to safety follow-up. By this time, all patients had completed their 104-week follow-up 
and, consequently, the discontinuation does not impact the data presented here.

Patients were randomised (1:1:1) to receive rituximab $2 \times 500 \mathrm{mg}+$ MTX, $2 \times 1000 \mathrm{mg}+$ MTX or placebo+MTX. Rituximab or placebo was administered by intravenous infusion on days 1 and 15. Patients received intravenous methylprednisolone $100 \mathrm{mg}$ premedication before all infusions. Oral MTX was commenced in all patients at $7.5 \mathrm{mg} /$ week and escalated to $20 \mathrm{mg} /$ week by week 8 , as tolerated. Repeat courses of rituximab or placebo were permitted from week 24 . To be eligible for re-treatment, patients had to have a Disease Activity Score in 28 joints (DAS28-erythrocyte sedimentation rate (ESR)) $\geq 2.6$, with further re-treatment permitted 24 weeks after each course based on the same criteria. The placebo-controlled period continued to week 104. At week 52, the sponsor was unblinded to all treatment assignments for the purposes of data analysis, but investigators, sites, patients and radiographic readers remained blinded. Radiographs (hands, wrists and feet) were performed at screening and weeks 24, 52 and 104 and were read by two independent expert radiologists using the Genant-modified Sharp scoring system. ${ }^{14} 15$

The primary end point was the change in total Genantmodified Sharp score (mTSS) at week 52 from baseline. ${ }^{12}$ At week 104, radiographic end points included the change in mTSS, total erosion score and joint space narrowing from baseline to week 104. Proportions of patients with no progression in mTSS and erosion scores were also assessed. Clinical end points included the proportion of patients achieving American College of Rheumatology (ACR)20/50/70/90 criteria responses, European League Against Rheumatism (EULAR) responses and change in DAS28-ESR. ACR index of improvement in RA (ACRn) was calculated as described previously. ${ }^{16}$ Physical function was assessed using the Health Assessment Questionnaire-Disability Index (HAO-DI). Radiographic outcomes and ACR50 responses were also analysed by serological status (RF and/or anticitrullinated peptide antibody (ACPA) presence). Adverse events (AEs) were recorded throughout the study and graded according to the National Cancer Institute Common Terminology Criteria for Adverse Events (version 3).

\section{STATISTICAL ANALYSIS}

Radiographic end points were analysed using a modified intention-to-treat population (all randomised and treated patients with a screening and at least one postbaseline radiographic evaluation). The intention-to-treat population (all patients randomised and treated) was used for all other efficacy and all safety end points.

Efficacy end points were grouped and ranked according to three objectives (prevention of joint damage, improvement in clinical signs and symptoms and improvement in physical function). All clinical signs and symptoms end points at week 104 were defined as exploratory in the protocol. Within the other two categories, all end points were secondary or exploratory at week 104, using a hierarchical approach to significance testing to control for multiplicity. When an end point did not reach significance at week 52, that end point and all end points lower in the hierarchy were treated as exploratory at week 104 . When a secondary end point did not reach significance at week 104, all end points lower in the hierarchy were treated as exploratory. The primary end point (change in mTSS vs placebo at week 52) was achieved for rituximab $2 \times 1000 \mathrm{mg}+$ MTX; however, the change in mTSS with rituximab $2 \times 500 \mathrm{mg}+$ MTX was not statistically significant. Therefore, all p-values associated with radiographic outcomes at week 104 for this lower dose are exploratory and should be interpreted with caution. Exploratory p-values are denoted by 'ex-p'.

Changes in radiographic scores were assessed with pairwise comparisons using a non-parametric test (Van Elteren) adjusted for baseline stratification factors (RF and region). Missing values were imputed by linear extrapolation. Percentage of inhibition of radiographic progression was calculated as (mean mTSS change in placebo group-mean mTSS change in a rituximab group) $\times 100 /$ (mean mTSS change in placebo group). Differences in the proportions of patients without radiographic progression were assessed using the Cochran-Mantel-Haenszel test, adjusting for baseline stratification factors. Patients were deemed to have progressed if their progression status could not be determined. Clinical signs and symptoms and physical efficacy differences were assessed using the Cochran-Mantel-Haenszel test and analysis of variance for categorical and continuous end points, respectively, adjusting for baseline stratification factors. Endpoint baseline values were included in analysis-of-variance models, if applicable. Non-responder imputations were used for categorical end points, and last observation carried forward was used for continuous end points.

\section{RESULTS}

A total of 755 patients were randomised, with 748 included in the intention-to-treat and safety population and 716 in the modified intention-to-treat population analysed for radiographic outcomes. Overall, 606 patients (80\%) completed week 104; lack of efficacy and refusal of treatment were the most common reasons for withdrawal, with $4 \%, 3 \%$ and $5 \%$ of patients in the rituximab $2 \times 500 \mathrm{mg}+$ MTX, $2 \times 1000 \mathrm{mg}+$ MTX and placebo+MTX groups, respectively, withdrawing due to safety reasons. The proportion of randomised patients completing week 104 was higher in the rituximab $2 \times 500 \mathrm{mg}+$ MTX and $2 \times 1000 \mathrm{mg}+$ MTX groups compared with the placebo+MTX group ( $85 \%$ and $85 \%$ vs $71 \%$, respectively). At 2 years, $67-68 \%$ of patients had received a third course of treatment, with some patients receiving up to five courses. The number of courses received was balanced between the placebo and rituximab treatment groups; overall, 249, 250 and 249 patients in the rituximab $2 \times 500 \mathrm{mg}+$ MTX, $2 \times 1000 \mathrm{mg}+$ MTX and placebo+MTX groups, respectively, received $\geq 1$ course; 215,219 and 212 received $\geq 2$ courses; 169, 172 and 169 received $\geq 3$ courses; 106, 107 and 122 received $\geq 4$ courses; and 24,26 and 31 received $\geq 5$ courses. Baseline characteristics were similar across all treatment groups and have been reported previously. ${ }^{12}$ As at 1 year, MTX doses were similar across groups at 2 years.

\section{Radiographic end points}

At week 104, rituximab $2 \times 1000 \mathrm{mg}+$ MTX continued to inhibit progressive joint damage (PJD) in patients. The change in mTSS from baseline was 0.41 for patients treated with rituximab $2 \times 1000$ mg+MTX compared with 1.95 in the placebo+MTX group ( $p<0.0001$ ), equating to $79 \%$ inhibition in mTSS (figure 1 ). Change from baseline in total erosion score also continued to be significantly lower with rituximab $2 \times 1000 \mathrm{mg}+$ MTX versus placebo+MTX at this time point (mean change 0.23 vs $1.32 ; \mathrm{p}<0.0001$ ) (figure 1). Furthermore, a positive effect on joint space narrowing scores was observed with rituximab $2 \times 1000 \mathrm{mg}+\mathrm{MTX}$ versus placebo+MTX (0.18 vs 0.63 ; $\mathrm{ex}-\mathrm{p}=0.0183$ ), an effect that was not seen at week 52 (figure 1). Also, contrary to the results observed at week 52 , exploratory analysis showed that PJD was reduced in patients receiving rituximab $2 \times 500 \mathrm{mg}+\mathrm{MTX}$ over the 2 -year time period: change in mTSS was reduced by approximately $61 \%$ compared with 


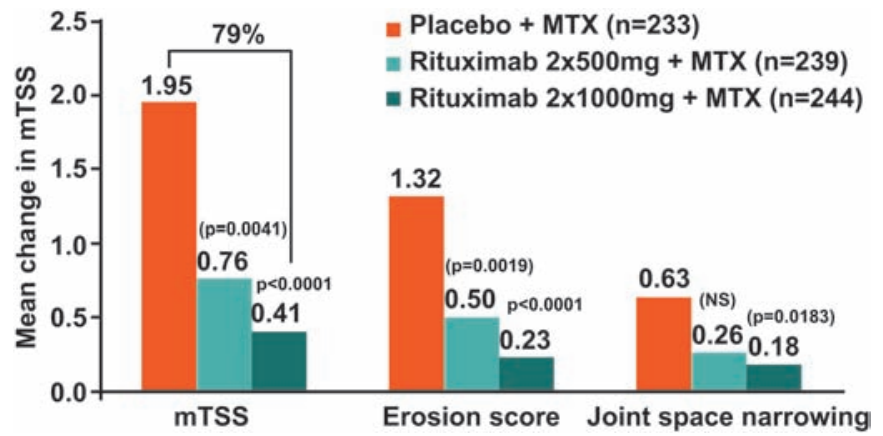

Figure 1 Change in radiographic end points at 2 years in the modified intention-to-treat population. Linear extrapolation used for missing values. Adjusted $p$-values comparing rituximab $+M T X$ groups with the placebo + MTX group; values in parentheses are unadjusted, exploratory p-values. mTSS, total Genant-modified Sharp score; MTX, methotrexate; NS, non-significant.

placebo+MTX (ex-p=0.0041), and erosive progression was slowed (mean change 0.50; ex-p=0.0019) (figure 1).

As observed at 1 year, a significantly higher proportion of patients receiving rituximab $2 \times 1000 \mathrm{mg}+$ MTX showed no radiographic progression (defined as change in $\mathrm{mTSS} \leq 0$ ) over 2 years compared with those receiving placebo+MTX $(57 \%$ vs $37 \%$; $<0.0001)$. In an exploratory analysis, a higher proportion of patients in the rituximab $2 \times 500 \mathrm{mg}+$ MTX group also showed no progression compared with the placebo+MTX group ( $49 \%$ vs $37 \%$; ex-p=0.0059). Across both rituximab groups, $82 \%$ of patients with no radiographic progression at week 52 maintained this status to week 104 compared with $64 \%$ in the placebo group. A higher proportion of patients in the rituximab $2 \times 500 \mathrm{mg}$ and $2 \times 1000 \mathrm{mg}+$ MTX groups had no increase in erosion score at week 104 compared with the placebo+MTX group $(53 \%, 59 \%$ and $38 \%$, respectively; ex-p<0.001 and $\mathrm{p}<0.0001)$.

As previously reported, the majority of joint damage observed in rituximab-treated patients occurred between baseline and 24 weeks. ${ }^{12}$ Thereafter, minimal further change occurred in both rituximab groups, whereas joint damage progression continued in a near-linear fashion in the placebo group (figure $2 \mathrm{~A}$ ). Annualised rates of progression of mTSS further demonstrated the markedly slowed disease progression from week 24 into the second year of treatment in both rituximab groups compared with the placebo group (figure 2B). From week 24 to week 104, rituximab $2 \times 1000 \mathrm{mg}+$ MTX demonstrated near-complete inhibition ( $97 \%$ ) of PJD compared with placebo+MTX (0.02 vs 0.72 , respectively) and rituximab $2 \times 500 \mathrm{mg}+$ MTX induced $90 \%$ inhibition of PJD versus placebo+MTX ( 0.07 vs 0.72 , respectively).

This study was not powered to compare outcomes between rituximab doses; however, in an exploratory analysis, all radiographic end points assessed from screening to week 104 for rituximab $2 \times 1000 \mathrm{mg}+$ MTX were numerically superior to rituximab $2 \times 500$ mg+MTX (online supplementary table S1).

\section{Clinical signs and symptoms}

Exploratory analyses showed that the improved clinical outcomes observed after 52 weeks were maintained at 104 weeks in both rituximab groups compared with the placebo group. ACR20/50/70/90 responses were achieved by higher proportions of patients in each rituximab group compared with the placebo group over the 2 years (figure $3 \mathrm{~A}-\mathrm{D}$ ). In addition, mean ACRn was higher at week 104 in the rituximab groups, and a larger proportion of patients achieved a major clinical response

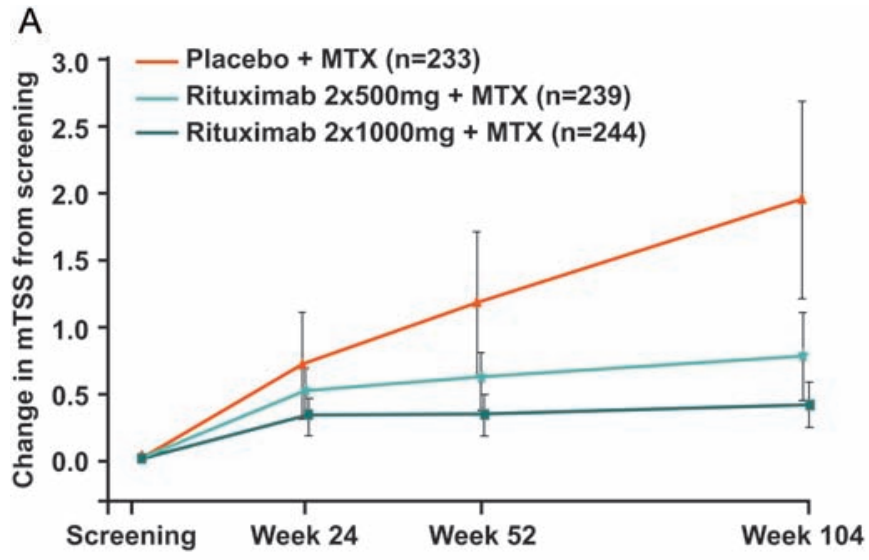

B
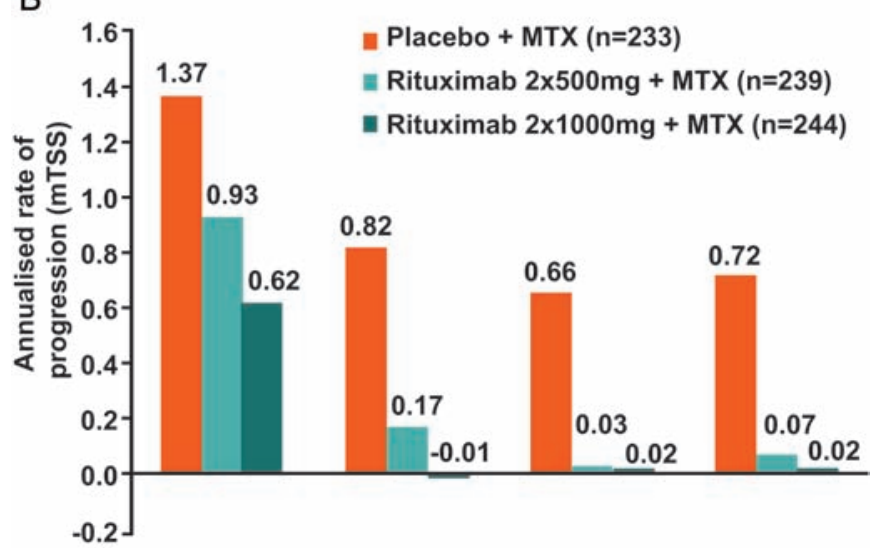

Screening to Wk24 Wk24 to Wk52 Wk52 to Wk104 Wk24 to Wk104

Figure 2 Rate of radiographic progression (change in mTSS) over 2 years. (A) Mean change in mTSS. Linear extrapolation used for missing data. Error bars show $\pm 1.96 \times$ standard error. (B) Annualised rate of progression of $\mathrm{mTSS}$ (all observed data). mTSS, total Genant-modified Sharp score; MTX, methotrexate.

(ACR70 maintained for at least six consecutive months) in each rituximab group compared with the placebo group (table 1).

Greater improvements in disease activity (as measured by mean change in EULAR response and DAS28-ESR) were also observed to week 104 in both rituximab+MTX groups compared with the placebo+MTX group (figure 3E,F). Almost two times more patients achieved a EULAR good response or DAS28-ESR clinical remission with rituximab+MTX compared with placebo+MTX (table 1). The proportions of patients with LDA and remission continued to increase over time in all treatment groups, but the increases were greatest in the rituximab+MTX groups.

\section{Physical function}

Improvements in physical function were also sustained throughout the second year of treatment with both rituximab+MTX doses resulting in significantly greater mean decreases in $\mathrm{HAQ}-\mathrm{DI}$ score compared with placebo+MTX $(p<0.0001$ at week 104) (figure 4). At week 104, exploratory analysis indicated that the proportion of patients with at least a minimal clinically important difference in $\mathrm{HAQ}$-DI (decrease $\geq 0.22$ ) was greater in the rituximab $2 \times 1000 \mathrm{mg}+$ MTX group than in the placebo+MTX group (table 1); proportions of patients achieving more marked improvements (ie, decreases of $\geq 0.3$ or $\geq 0.5$ ) were also greater in the rituximab $2 \times 1000 \mathrm{mg}+\mathrm{MTX}$ group (data not shown). While the proportion of patients in the rituximab $2 \times 500 \mathrm{mg}+$ MTX group achieving the minimal clinically important difference in 

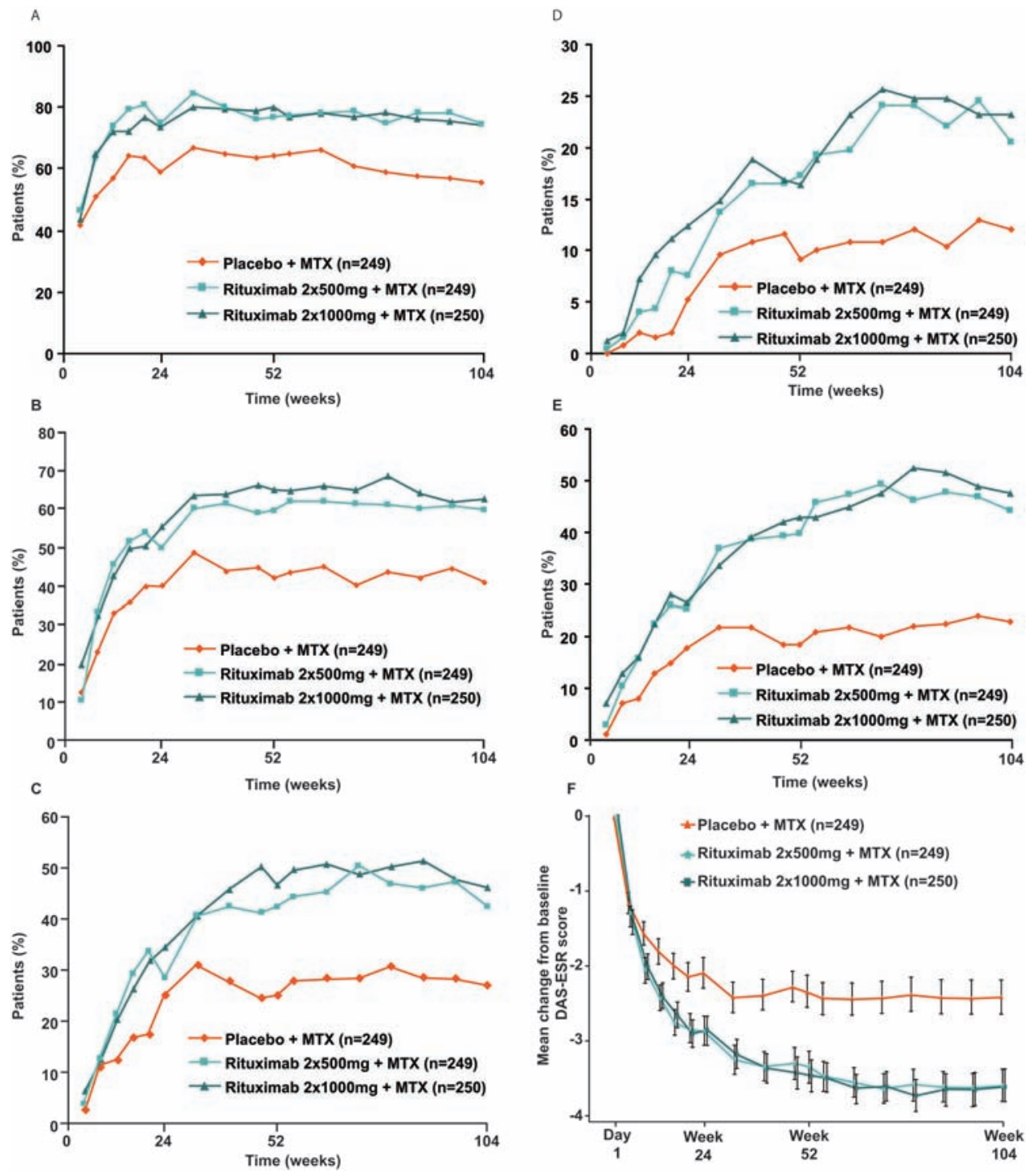

Figure 3 Efficacy over 2 years. (A) ACR20, (B) ACR50, (C) ACR70 and (D) ACR90 responses. LOCF used for tender and swollen joint counts, HAO score, CRP, ESR and VAS assessments. ACRn was set to 'non-responder' when the score was missing. Patients were classified as non-responders from the point of withdrawal or rescue use. (E) EULAR good response. LOCF used for tender and swollen joint counts, ESR and patient's Global Assessment of Disease Activity VAS. EULAR response was set to 'non-responder' when the DAS28 score was missing. Patients were classified as non-responders from the point of withdrawal or rescue use. (F) Mean change in DAS28. LOCF used for tender and swollen joint counts, ESR and patient's Global Assessment of Disease Activity VAS. Error bars show $\pm 1.96 \times$ standard error. ACR, American College of Rheumatology; CRP, C reactive protein; DAS28, Disease Activity Score in 28 joints; ESR, erythrocyte sedimentation rate; EULAR, European League Against Rheumatism; HAO, Health Assessment Questionnaire; LOCF, last observation carried forward; MTX, methotrexate; VAS, visual analogue scale.

HAQ-DI was numerically higher than in the placebo group, this did not reach statistical significance.

\section{Efficacy in subgroups}

Subgroup analysis was performed on data from patients seropositive or seronegative for RF and/or ACPA. At week 104, RF and/or ACPA seropositive patients treated with rituximab+MTX had a greater probability of having no radiographic progression, and a greater proportion achieved an ACR50 response, compared with patients receiving MTX alone. In seronegative patients, rituximab treatment had a less pronounced effect on radiographic responses and no effect on clinical responses. Comparisons between treatment groups should be interpreted with caution due to small numbers of seronegative patients and overlapping CI. Results are presented in online supplementary table S2.

\section{Safety}

Safety data over 104 weeks were consistent with those observed at 52 weeks with no new safety signals observed. The overall safety profile of rituximab+MTX was similar to that observed in the placebo+MTX group (table 2).

Withdrawals due to AEs were low: $3 \%$ in both rituximab groups compared with $7 \%$ in the placebo group. There was no predominant AE that led to withdrawal. Six deaths occurred during the 104-week study: three in the placebo+MTX group (two due to pneumonia and one due to cerebral infarction), two in the rituximab $2 \times 500 \mathrm{mg}+\mathrm{MTX}$ group (one due to pneumonia; primary cause of death was unknown/unobtainable in the other-the patient had breathing difficulties and subsequently died in the hospital) and one in the rituximab $2 \times 1000 \mathrm{mg}+$ MTX group (due to duodenal ulcer). The incidence of all/serious AEs and rates of all/serious infections were similar across all treatment groups (table 2). Proportions of patients experiencing 
Table 1 Summary of clinical and physical function efficacy outcomes over 104 weeks (intention-to-treat population)

\begin{tabular}{|c|c|c|c|}
\hline Outcome & $\begin{array}{l}\text { Placebo+MTX } \\
(n=249)\end{array}$ & $\begin{array}{l}\text { Rituximab } 2 \times 500 \mathrm{mg}+\mathrm{MTX} \\
(\mathrm{n}=249)\end{array}$ & $\begin{array}{l}\text { Rituximab } 2 \times 1000 \mathrm{mg}+\mathrm{MTX} \\
(\mathrm{n}=250)\end{array}$ \\
\hline \multicolumn{4}{|l|}{ Disease activity } \\
\hline Major clinical response ${ }^{\dagger}(\%)$ & 22 & $39 * *$ & $40^{* *}$ \\
\hline Mean ACRn $n^{\ddagger}$ & 30.7 & 55.4 & 58.5 \\
\hline EULAR good response (\%) & 23 & $44^{* *}$ & $48^{* *}$ \\
\hline DAS28 LDA (\%) & 25 & $45^{* *}$ & $48^{* *}$ \\
\hline DAS28 remission (\%) & 13 & $34^{* *}$ & $32^{* *}$ \\
\hline \multicolumn{4}{|l|}{ Physical function } \\
\hline HAQ-DI decrease $\geq 0.22(\%)$ & 77 & 84 & $86^{*}$ \\
\hline
\end{tabular}

${ }^{*} p<0.05,{ }^{* *} p<0.0001$ versus placebo+MTX. All p-values are exploratory/descriptive.

${ }^{\dagger}$ Major clinical response $=A C R 70 \geq 6$ months.

${ }^{\ddagger}$ Number of patients with non-missing ACRn assessments for all groups was 248 .

Analysis-of-variance model adjusted for stratification factors (RF status, region) (adjusted mean changes shown in the table);

Cochran-Mantel-Haenszel test was used for categorical variables, non-responder imputation was used for ACR major clinical

response and EULAR response variables and last observation carried forward was used for DAS28 LDA, DAS28 remission and HAQ-DI.

ACRn, American College of Rheumatology index of improvement in RA; DAS28, Disease Activity Score in 28 joints; EULAR,

European League Against Rheumatism; HAQ-DI, Health Assessment Questionnaire-Disability Index; LDA, low disease activity; MTX,

methotrexate; RF, rheumatoid factor.



Figure 4 Mean change in HAQ-DI over 2 years. LOCF was used for missing data. Error bars show $\pm 1.96 \times$ standard error. HAQ-DI, Health Assessment Questionnaire-Disability Index; LOCF, last observation carried forward; MTX, methotrexate.

at least one $\mathrm{AE}$ by treatment course were also comparable across all treatment groups (table 2). Infusion-related reactions remained the most common $\mathrm{AE}$ and were more frequent with the first infusion of the first course, declining thereafter. Serious infections were reported slightly more frequently in the placebo group ( $8 \%$ ) than in either rituximab group (5\% both groups). Three serious opportunistic infections occurred before week 52 (one case of Pneumocystis jiroveci pneumonia and one case of Candida albicans in the rituximab $2 \times 500 \mathrm{mg}+\mathrm{MTX}$ group; one case of pneumonia due to Pseudomonas aeruginosa/Pneumocystis carinii in the placebo+MTX group). No further serious opportunistic infections were reported between week 52 and week 104.

\section{DISCUSSION}

Treatment with rituximab $2 \times 1000 \mathrm{mg}$ in combination with MTX has previously been shown to result in significant inhibition of PJD over 1 year in MTX-naive patients with early, active RA. ${ }^{12}$ The current analysis reports that these effects, including significant reductions in mTSS and erosion score, are maintained over 2 years of treatment with rituximab $2 \times 1000 \mathrm{mg}+$ MTX. Exploratory analysis also suggested that rituximab $2 \times 500 \mathrm{mg}+\mathrm{MTX}$ slowed joint damage over 2 years.
The proportion of patients showing no progression of joint damage after 2 years was significantly higher in the rituximab dose groups compared with the placebo+MTX group. The figure of $57 \%$ observed for the $2 \times 1000 \mathrm{mg}$ dose was almost identi$\mathrm{cal}(56.8 \%)$ to that seen at 2 years in a similar population treated with abatacept+MTX. ${ }^{17}$ The majority of joint damage progression in the current study was observed within the first 6 months, with further damage almost entirely prevented thereafter; the reasons for this are unknown.

Over 2 years, both doses of rituximab continued to demonstrate significant improvements over placebo in relieving the signs and symptoms of RA, as exemplified by significantly higher proportions of patients achieving 'high-hurdle' end points, such as ACR70 and ACR90, major clinical response, EULAR good response and DAS28 remission. In addition, improvements in physical function were maintained, with significantly greater mean changes in HAQ-DI observed in both rituximab groups than in the placebo group throughout the observation period.

This study was not powered to compare rituximab doses, but exploratory results generally show that numerically greater responses for radiographic outcomes were achieved with the higher dose, while clinical outcome responses were generally numerically similar for both doses. In addition, the disconnect between radiographic and clinical responses with rituximab $2 \times 500 \mathrm{mg}+$ MTX previously observed at 1 year was reduced at 2 years - an effect attributed to a slower onset of radiographic inhibition during the initial 6 months of treatment with the 500 -mg dose. A recent consensus statement ${ }^{18}$ discussed the optimal dose of rituximab in patients with RA. The authors proposed that the 500-mg dose may provide equivalent clinical and radiographic benefits to $1000 \mathrm{mg}$; however, the 500-mg dose is not approved and has not been studied in the licensed TNF-IR patient population. Consequently, further analysis would be required to confirm any equivalence of doses. In the present study, while both rituximab doses provided benefit in improving clinical signs and symptoms, data suggest that the higher dose slows PJD sooner, an observation that is relevant to an early population with RA (data presented in online supplementary table S1).

As at 1 year, and consistent with observations made in other patient populations, ${ }^{19-21}$ patients in the small subgroup who were seronegative for both RF and ACPA showed limited evidence of radiographic or clinical improvement with rituximab+MTX or 
Table 2 Summary of safety profile over 104 weeks (safety population)

\begin{tabular}{|c|c|c|c|}
\hline & $\begin{array}{l}\text { Placebo+MTX } \\
(n=249)\end{array}$ & $\begin{array}{l}\text { Rituximab } 2 \times 500 \\
m g+\text { MTX }(n=249)\end{array}$ & $\begin{array}{l}\text { Rituximab } 2 \times 1000 \\
m g+\text { MTX }(n=250)\end{array}$ \\
\hline Patient-years of observation & 422.11 & 457.92 & 462.09 \\
\hline \multicolumn{4}{|l|}{ AE incidence, $n(\%)$} \\
\hline Any AE & $215(86)$ & $206(83)$ & $217(87)$ \\
\hline First course $e^{*}$ & $183(73)$ & $167(67)$ & $188(75)$ \\
\hline Second course $e^{*}$ & $135(64)$ & $128(60)$ & $140(64)$ \\
\hline Third course ${ }^{*}$ & $107(63)$ & $96(57)$ & $111(65)$ \\
\hline Fourth course ${ }^{*}$ & $52(43)$ & $55(52)$ & $55(51)$ \\
\hline Fifth course ${ }^{*}$ & $5(16)$ & $7(29)$ & $8(31)$ \\
\hline Any serious AE (all courses) & $42(17)$ & $37(15)$ & $33(13)$ \\
\hline AE leading to withdrawal (all courses) & $17(7)$ & $8(3)$ & $7(3)$ \\
\hline All deaths ${ }^{\dagger}$ & $3(1)$ & $2(<1)$ & $1(<1)$ \\
\hline \multicolumn{4}{|l|}{ Infusion-related reaction, $\mathrm{n}(\%)$} \\
\hline First course $e^{*}$ & $31(12)$ & $35(14)$ & $46(18)$ \\
\hline Second course* & $21^{\ddagger}(10)$ & $20(9)$ & $21(10)$ \\
\hline Third course* & $10(6)$ & $11(7)$ & $12(7)$ \\
\hline Fourth course ${ }^{*}$ & $10(8)$ & $10(9)$ & $8(7)$ \\
\hline Fifth course $e^{*}$ & $2(6)$ & $1(4)$ & $3(12)$ \\
\hline \multicolumn{4}{|l|}{ Infection, n (\%) } \\
\hline Any & $146(59)$ & $162(65)$ & $160(64)$ \\
\hline Serious ${ }^{\S}$ & $19(8)$ & $13(5)$ & $12(5)$ \\
\hline \multicolumn{4}{|l|}{ Malignancy, n (\%) } \\
\hline Any & $7(3)$ & $6(2)$ & $3(1)$ \\
\hline Serious & $6(2)$ & $5(2)$ & $2(<1)$ \\
\hline \multicolumn{4}{|l|}{$\mathrm{AE}$ rates per 100 patient-years $(95 \% \mathrm{Cl})$} \\
\hline Overall infection rate & 99.50 (90.42 to 109.49 ) & 92.37 (83.98 to 101.61$)$ & 109.50 (100.36 to 119.47$)$ \\
\hline Serious infection ${ }^{\S}$ rate & 4.97 (3.24 to 7.63$)$ & 4.15 (2.65 to 6.50$)$ & 3.25 (1.96 to 5.38$)$ \\
\hline
\end{tabular}

placebo+MTX treatment. Conversely, radiographic and clinical responses among patients seropositive for RF and/or ACPA were significantly improved for rituximab compared with MTX alone.

The 2-year safety profile is consistent with that observed at 1 year $^{12}$ and with previously reported data in TNF-IR patients ${ }^{79}$ and pooled data from long-term rituximab studies. ${ }^{22}$ The incidence of serious infections remained low and consistent with previously reported rates, ${ }^{22}$ and no further opportunistic infections were reported beyond those observed up to week 52 . Infusion-related reactions remained the most common safety event overall; however, their incidence generally declined following the first infusion of the first course.

No cases of PML were reported in this trial, and the overall reporting incidence of PML in patients with RA receiving rituximab is very rare (5 cases in 129,000 patients with RA). ${ }^{23}$ The IMAGE trial was conducted in MTX-naive patients with early disease, and many alternative treatment options are available for these patients; therefore, following a spontaneous report of a case of PML in a rituximab-treated patient not previously exposed to biological treatment, ${ }^{24}$ the sponsors took the decision to discontinue dosing with rituximab in the IMAGE trial.

Rituximab $2 \times 1000 \mathrm{mg}$ is currently licensed in combination with MTX for patients with RA who have had an IR or intolerance to other disease-modifying antirheumatic drugs, including one or more TNF inhibitor treatments. Rituximab is not approved for use in the MTX-naive population described here, but these data demonstrate the value of rituximab+MTX in preventing progression of structural joint damage, a key goal of treatment. Furthermore, under recent recommendations and guidelines, patients often now receive their second and subsequent biological treatment much sooner after RA diagnosis. ${ }^{3} 4$ Consequently, the positive results presented here for the IMAGE trial, in which patients were treated on average 1 year after RA disease onset, may be relevant to a TNF-IR patient who initiates treatment with rituximab.

In conclusion, this 2-year analysis of the IMAGE study demonstrates that rituximab $2 \times 1000 \mathrm{mg}+$ MTX led to sustained and significant inhibition of joint damage progression and significant improvements in clinical signs and symptoms of RA and functional ability compared with MTX alone in an early population of patients with RA.

Contributorship PPT monitored data collection, analysed the data and implemented the trial. He is guarantor. WR monitored data collection, analysed the data and implemented the trial. ARR monitored data collection, analysed the data and implemented the trial. CP monitored data collection, analysed the data and implemented the trial. RFvV monitored data collection, analysed the data and implemented the trial. WS monitored data collection, analysed the data and implemented the trial. E Healy monitored data collection, cleaned and analysed the data and implemented the trial. E Hessey wrote the statistical analysis plan and cleaned and analysed the data. MR monitored data collection, cleaned and analysed the data and implemented the trial. TS designed the study and data collection tools, cleaned and analysed the data and implemented the trial. All authors contributed to the development of the manuscript and read and approved the final version. Laura Burke (Roche) monitored data collection, cleaned and analysed the data, implemented the trial and contributed to the development of the manuscript. Nicola Tyson (Roche) wrote the statistical analysis plan, cleaned and analysed the data and contributed to the development of the manuscript.

Acknowledgements The authors thank Laura Burke and Nicola Tyson (Roche Products) who contributed to the analysis and interpretation of the data. Radiographs were read at a central reading facility (Synarc Inc, San Francisco, California, USA). 
Support for third-party writing assistance for this manuscript was provided by F Hoffmann-La Roche.

Funding Financial support for this study was obtained from F Hoffmann-La Roche, Genentech Inc and Biogen Idec.

Competing interests PPT has served as a consultant to Roche and Genentech. WR has served as a paid consultant for Roche, Genentech and Biogen Idec; has been paid lecture fees by Genentech and Biogen Idec; and has received grant support from Roche. ARR has received honoraria for talks and consulting from Roche. CP is an employee and shareholder of Spire Sciences LLC and a shareholder of Synarc Inc, which provide clinical trials services for multiple pharmaceutical, biotechnology and medical device companies. RFvV has received research support and honoraria/consultancy from Abbott, Merck, Pfizer, Roche and UCB Pharma, as well as honoraria/consultancy from Bristo Myers Squibb. WS has received a research grant from Xencor. E Healy is an employee of and owns shares in Roche. E Hessey is an employee of Roche. MR was an employee of Roche at the time of trial conduct and manuscript preparation, owns shares in Roche and is now an employee of and owns shares in GlaxoSmithKline. TS was an employee of Roche at the time of trial conduct and manuscript preparation, owns shares in Roche and is now an employee of Celgene Corporation.

Provenance and peer review Not commissioned; externally peer reviewed.

\section{REFERENCES}

1. Yelin E, Trupin L, Wong B, et al. The impact of functional status and change in functional status on mortality over 18 years among persons with rheumatoid arthritis. $J$ Rheumatol 2002;29:1851-7.

2. Wolfe F, Michaud K, Gefeller 0 , et al. Predicting mortality in patients with rheumatoid arthritis. Arthritis Rheum 2003;48:1530-42.

3. Smolen JS, Aletaha D, Bijlsma JW, et al. Treating rheumatoid arthritis to target: recommendations of an international task force. Ann Rheum Dis 2010;69:631-7.

4. Smolen JS, Landewé R, Breedveld FC, et al. EULAR recommendations for the management of rheumatoid arthritis with synthetic and biological disease-modifying antirheumatic drugs. Ann Rheum Dis 2010;69:964-75.

5. van der Heijde D, Landewé R, van Vollenhoven $R$, et al. Level of radiographic damage and radiographic progression are determinants of physical function: a longitudinal analysis of the TEMPO trial. Ann Rheum Dis 2008;67:1267-70.

6. Emery P, Fleischmann R, Filipowicz-Sosnowska A, et al. The efficacy and safety of rituximab in patients with active rheumatoid arthritis despite methotrexate treatment: results of a phase IIB randomized, double-blind, placebo-controlled, dose-ranging trial. Arthritis Rheum 2006;54:1390-400.

7. Emery P, Deodhar A, Rigby WF, et al. Efficacy and safety of different doses and retreatment of rituximab: a randomised, placebo-controlled trial in patients who are biological naive with active rheumatoid arthritis and an inadequate response to methotrexate (Study Evaluating Rituximab's Efficacy in MTX iNadequate rEsponders (SERENE)). Ann Rheum Dis 2010;69:1629-35.
8. Rubbert-Roth A, Tak PP, Zerbini C, et al. Efficacy and safety of various repeat treatment dosing regimens of rituximab in patients with active rheumatoid arthritis: results of a Phase III randomized study (MIRROR). Rheumatology (Oxford) 2010;49:1683-93

9. Cohen SB, Emery P, Greenwald MW, et al. Rituximab for rheumatoid arthritis refractory to anti-tumor necrosis factor therapy: results of a multicenter, randomized, double-blind, placebo-controlled, phase III trial evaluating primary efficacy and safety at twenty-four weeks. Arthritis Rheum 2006;54:2793-806.

10. Keystone E, Emery P, Peterfy CG, et al. Rituximab inhibits structural joint damage in patients with rheumatoid arthritis with an inadequate response to tumour necrosis factor inhibitor therapies. Ann Rheum Dis 2009;68:216-21.

11. Cohen SB, Keystone E, Genovese MC, et al. Continued inhibition of structural damage over 2 years in patients with rheumatoid arthritis treated with rituximab in combination with methotrexate. Ann Rheum Dis 2010;69:1158-61.

12. Tak PP, Rigby WF, Rubbert-Roth A, et al. Inhibition of joint damage and improved clinical outcomes with rituximab plus methotrexate in early active rheumatoid arthritis: the IMAGE trial. Ann Rheum Dis 2011;70:39-46.

13. Rigby W, Ferraccioli G, Greenwald M, et al. Rituximab improved physical function and quality of life in patients with rheumatoid arthritis naïve to methotrexate (IMAGE study). Arthritis Care Res (Hoboken) 2010. In press.

14. Genant HK. Methods of assessing radiographic change in rheumatoid arthritis. Am J Med 1983;75(6A):35-47.

15. Genant HK, Jiang Y, Peterfy $C$, et al. Assessment of rheumatoid arthritis using a modified scoring method on digitized and original radiographs. Arthritis Rheum 1998;41:1583-90.

16. Siegel JN, Zhen BG. Use of the American College of Rheumatology N (ACR-N) index of improvement in rheumatoid arthritis: argument in favor. Arthritis Rheum 2005;52:1637-41.

17. Bathon J, Robles M, Ximenes AC, et al. Sustained disease remission and inhibition of radiographic progression in methotrexate-naive patients with rheumatoid arthritis and poor prognostic factors treated with abatacept: 2-year outcomes. Ann Rheum Dis 2011. In press.

18. Buch MH, Smolen JS, Betteridge N, et al. Updated consensus statement on the use of rituximab in patients with rheumatoid arthritis. Ann Rheum Dis 2011;70:909-20.

19. Sellam J, Hendel-Chavez $\mathrm{H}$, Rouanet $\mathrm{S}$, et al. B cell activation biomarkers as predictive factors for the response to rituximab in rheumatoid arthritis: a six-month, national, multicenter, open-label study. Arthritis Rheum 2011;63:933-8.

20. Isaacs JD, Ferraccioli $G$. The need for personalised medicine for rheumatoid arthritis. Ann Rheum Dis 2011;70:4-7.

21. Chatzidionysiou $\mathbf{K}$, Lie $\mathrm{E}$, Lukina $\mathrm{G}$, et al. Efficacy and safety of rituximab treatment in clinical practice: data from the CERERRA collaboration. Ann Rheum Dis 2011;70:1575-80.

22. van Vollenhoven R, Emery P, Bingham CO III, et al. Long-term safety of rituximab: follow-up of the rheumatoid arthritis clinical trials and retreatment population. Arthritis Rheum 2010;62(Suppl 10):S165

23. Clifford DB, Ances B, Costello C, et al. Rituximab-associated progressive multifocal leukoencephalopathy in rheumatoid arthritis. Arch Neurol 2011;68:1156-64.

24. US FDA Safety Information available at http://www.fda.gov/downloads/Safety/ MedWatch/Safetylnformation/SafetyAlertsforHumanMedicalProducts/UCM187792.pdf (accessed 26 September 2011) 